\title{
Chronic obstructive pulmonary disease in Brazilian primary care: diagnostic competence and case-finding
}

\author{
Raph Hamers ${ }^{a, *}$, Sander Bontemps ${ }^{a}$, Marjan van den Akker ${ }^{a}$, \\ Ruy Souza ${ }^{b}$, Júlio Penaforte ${ }^{c, d}$, Niels Chavannes ${ }^{a}$
}

a Care and Public Health Research Institute, Department of General Practice, Maastricht University, PO Box 616, 6200 MD Maastricht, The Netherlands

${ }^{b}$ Centre of Biological and Health Sciences, Federal University of Roraima, Brazil

c School of Public Health of Ceará, Brazil

d Innovare Institute for Education and Health, Fortaleza, Brazil

Received 19 April 2006; accepted 20 July 2006

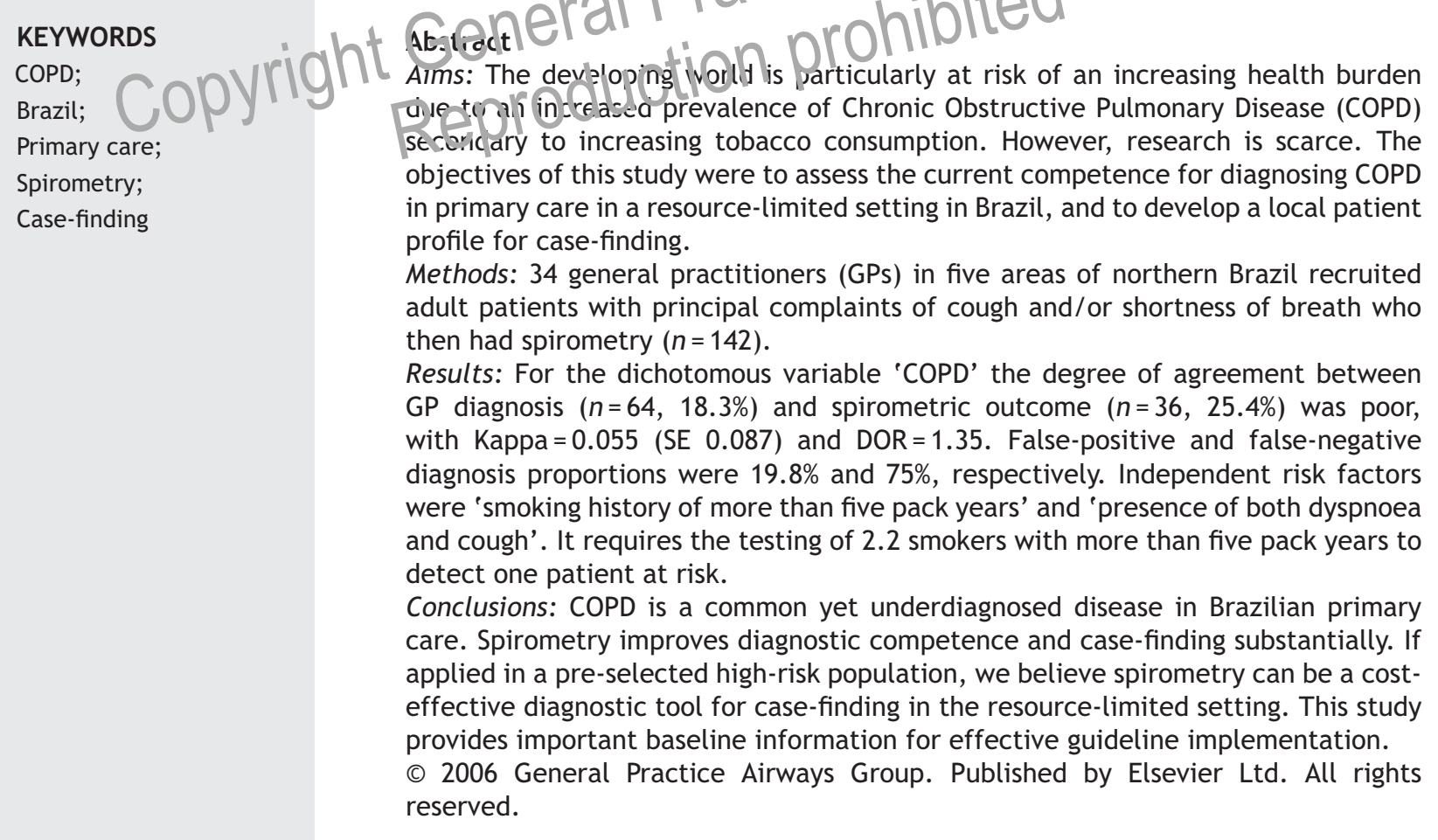
KEYWORDS
COPD;
Brazil
Ab:-100t
Arms: The devieloping vorld is varticularly at risk of an increasing health burden die tonalinceseas prevalence of Chronic Obstructive Pulmonary Disease (COPD) secovic ary to increasing tobacco consumption. However, research is scarce. The objectives of this study were to assess the current competence for diagnosing COPD in primary care in a resource-limited setting in Brazil, and to develop a local patient profile for case-finding.
Methods: 34 general practitioners (GPs) in five areas of northern Brazil recruited adult patients with principal complaints of cough and/or shortness of breath who . with Kappa $=0.055$ (SE 0.087) and $D O R=1.35$. False-positive and false-negative diagnosis proportions were $19.8 \%$ and $75 \%$, respectively. Independent risk factors were 'smoking history of more than five pack years' and 'presence of both dyspnoea and cough'. It requires the testing of 2.2 smokers with more than five pack years to detect one patient at risk.
Conclusions: COPD is a common yet underdiagnosed disease in Brazilian primary care. Spirometry improves diagnostic competence and case-finding substantially. If applied in a pre-selected high-risk population, we believe spirometry can be a cost- effective diagnostic tool for case-finding in the resource-limited setting. This study reserved.
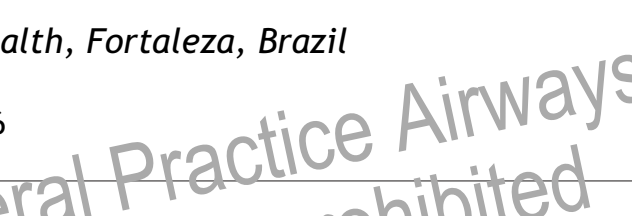

\footnotetext{
* Corresponding author. Tel.: +31 6 26466853; fax: +31 102931401.

E-mail address: rhamers@hotmail.com (R. Hamers).
} 


\section{Introduction}

Chronic Obstructive Pulmonary Disease (COPD) is an important cause of chronic morbidity and mortality throughout the world [1]. It is the fifth leading cause of death worldwide [2] and its burden is expected to increase further in the coming decades [3]. In the developing world public health has traditionally focussed on infectious diseases. However, the transition towards a burden of non-communicable diseases is ongoing [3]. The developing world is particularly at risk of a COPD epidemic, due to increased tobacco consumption which can be partly attributed to the efforts of tobacco companies to target the yet unexplored markets within these areas [4]. COPD is estimated to be the fourth leading cause of disability for males and the third leading cause of disability for females in developing countries by the year 2020 [3]. In addition, other associated factors such as low socio-economic status, outdoor and indoor air pollution, and frequent respiratory infection, contribute to the increasing burden of respiratory disease $[1,5]$. Moreover, the lack of diagnostic facilities and adequately trained physicians working at a community level constitute a great obstacle in establishing early diagnoses.

A recent study reported significant COPP prevalences throughout Latin Arerica, demonstrating that COPD is atirody anl important health problem there [6]. However, ressar $h$ in resource-linited settings iscarle, "winst COPD remains an underdiagnosed und undertreated disease [1].

Brazil is a developing country ranked 63rd on the United Nations Human Development Index 2003 [7]. It is characterised by marked regional differences, the north and northeast regions being the two least-developed regions accounting for the poorest socio-economic and health statistics [8]. COPD prevalence estimates in the general population range from $4.1 \%$ [9] to $15.8 \%$ [6], whereas smoking prevalences are recorded at $31.0 \%$ (35.4\% among men and $26.9 \%$ among women), with great regional variability [4].

The need for spirometry to establish a diagnosis of COPD is acknowledged by leading international guidelines $[10,11]$, including those specifically designed for primary care [12]. General practitioners (GPs) and their practice assistants have been shown to be capable of performing adequate spirometric measurements in the office and interpreting obstructive patterns, provided that they are well-trained $[13,14]$. Studies that have used spirometry to detect airflow obstruction at an early stage have reported considerable rates of previously unknown COPD cases [15-18]. To the best of our knowledge no reports have been published that have used and applied spirometry in a resource-limited setting with the aim of increasing case-finding.

The first objective of this study was to measure the prevalence of (chronic) respiratory diseases at a primary care level in the north and northeast regions of Brazil. Secondly, we aimed to assess the current diagnostic competence of GPs in terms of their ability to diagnose COPD. To this end, a comparison was made between GP diagnosis and the diagnostic 'gold standard' of spirometry. Ultimately, our final aim was to develop a local patient profile for efficient case-finding.

\section{Methods}

\section{Study setting and participants}

Thirty-four volunteering GPs were recruited from the Family Health Program (FHP) in five distinct urban and rural areas in the north and northeast regions of Brazil (Ceará and Roiliina states) (Table 1). The FHD Finfe sivgats are organised in health leam vinich consist of one GP, one niuse, sne auxiliary nurse, and six health agents, taking respprsibility for the identification of local heaith - lsks in a well-defined area [19]. The study period consisted of two six-month episodes between April 2002 and March 2004. The target population included all adults ( $\geq 15$ years) who attended the GP principally with symptoms of shortness of breath and/or cough, irrespective of the cause, smoking history, previous diagnosis, and duration of symptoms. All eligible patients who were encountered, both in the 'health post' clinic setting and during family visits, were sent to see the GP. A standardised one-page format subject form was filled out by the GP for each subject who matched inclusion criteria.

\section{Spirometry}

All enrolled patients were systematically invited to undergo spirometry. They either returned to the 'health post' or they were visited in their residence on an agreed day. Spirometric testing was performed by two field researchers (RH, SB), who had received extensive training on the execution of spirometry and the assessment of flow-volume loop (FVL) quality at the lung function laboratory of Maastricht University Hospital, the Netherlands. We used MicroLab $3300^{\circledR}$ spirometers (MicroMedical Limited, UK) which had been calibrated before the 
Table 1 Characteristics of participating general practitioners ${ }^{\mathrm{a}}$ (GPs) $\left(n=34^{\mathrm{b}}\right)$

\begin{tabular}{ll}
\hline Male/female & $21 / 13$ \\
Rural/Urban & $17 / 17$ \\
Years of GP working experience $^{c}$ (median, range) & $4.0(14.0)$ \\
Post-graduate training in public health/primary care $^{d}$ (\% of GPs) & $14.3 \%$ \\
No. of patients included per GP (mean \pm SD) & $13.9( \pm 11.8)$ \\
No. of spirometries per GP (mean \pm SD) & $4.6( \pm 6.6)$
\end{tabular}

a GPs were from the following municipalities: Fortaleza $(n=4)$, Pedra Branca $(n=7)$, Tianguá $(n=8)$, Ubajara $(n=2)$, and Boa Vista $(n=13)$. None of them had received any additional specific training on COPD, peak flow or spirometry.

b Two GPs were kept out of the study due to the exclusion of their patients (insufficient data).

c Based on data of 13 GPs.

d Based on data of 21 GPs.

study. Spirometric testing followed the American Thoracic Society recommendations [20], and included baseline and reversibility testing. Subjects were tested on one occasion, at least six weeks after a possible period of exacerbation. The attempt with the highest baseline $\mathrm{FEV}_{1}$, out of a minimum of three reproducible attempts, was selected for analysis. Irreversible obstruction was defined as post-bronchodilation $\mathrm{FEV}_{1} / \mathrm{FVC}<70 \%$, according to GOLD criteria [10]. Since reference values for the Brazilian population are not available, we used those for Caucasians [21].

\section{Outcome measures}

For descriptive purposes, + G 7 (nagnoses were classified in the follov' no six ouccome categoriest. (1) respirato Infection; 2 raltira; (3) tuberculosis; (4) restrictive Fondition, including both parenchymal (e.g. fibrotic disease) and extraparenchymal (e.g. chest wall, respiratory muscles and pleura) disorders; (5) COPD; and (6) other pathology (i.e. rare and non respiratory). Spirometry readings were scored on the basis of both visual inspection of the FVL and values of $\mathrm{FEV}_{1}$ and FVC (NC). Spirometry results were classified into the following six outcome categories: (1) incorrect test manoeuvre; (2) normal lung function; (3) reversible obstruction (e.g. asthma); (4) suggestive of restriction (restrictive pattern, $\mathrm{FVC}<80 \%$ and normal $\mathrm{FEV}_{1}$ ); (5) irreversible obstruction (i.e. COPD); and (6) other pathology (i.e. rare and non respiratory). The GP diagnoses and spirometric outcomes were also dichotomised as 'COPD yes or no'.

\section{Statistical analysis}

We performed bivariate analysis to investigate the degree of agreement (Kappa statistic and diagnostic odds ratio, DOR) between 'GP diagnosis' and 'spirometric outcome' for the dichotomous variable 'COPD' and to test risk factors for predicting COPD. Results were expressed as odds ratios (OR) with $95 \%$ confidence intervals $(95 \% \mathrm{Cl})$ and positive predictive values (PPV). Multiple logistic regression analysis with stepwise backward procedure was performed to test risk factors for predicting the spirometric outcome of COPD. Independent variables were: sex; age groups; symptoms (only dyspnoea, only cough and both); pack year groups; ever smoker; current smoker; and setting (rural/urban). For statistical analysis we used the SPSS ${ }^{\circledR}$ software pac'irige liversion 8.0 for Windows

\section{Results}

\section{Participation and distribution}

Seven $(2.0 \%)$ of 357 subjects were excluded from analysis due to insufficient data. Of the remaining 350 subjects, men comprised $45.1 \%$. Mean age for all was $46.8(S D \pm 18.7)$ years. Lifetime prevalence of smoking was $57.7 \%$, with a mean of $9.4(S D \pm 16.4)$ pack years. 64 subjects (18.3\%) had a GP diagnosis of COPD (Table 2). One hundred and fifty-seven subjects $(44.9 \%)$ underwent spirometry (SPIRO group). SPIRO and NONSPIRO subjects did not differ in terms of sex distribution, pack years, and proportion of presence of both cough and dyspnoea (as opposed to only one respiratory symptom). GP diagnoses were also equally distributed between the two subgroups with the exception of respiratory infection, which was less prevalent in the SPIRO group. In the SPIRO group, age over 55 years, and education level beyond secondary school, were over-represented (Table 2). Fifteen (9.6\%) spirometries did not meet quality criteria and were rejected. Outcome of the 142 valid spirometries was as follows: COPD in $25.4 \%(n=36)$; normal lung function in $43.7 \%$; reversible obstruction in $19.0 \%$; and restriction in $12.0 \%$. 
Table 2 Patient characteristics for all enrolled patients $(n=350)$, for those who had spirometry (SPIRO, $n=157)$, and for those did not have spirometry (NONSPIRO, $n=193$ )

\begin{tabular}{|c|c|c|c|c|}
\hline & Total & SPIRO & NONSPIRO & OR $(95 \% \mathrm{Cl})$ \\
\hline Total & 350 & $157(44.9 \%)$ & $193(55.1 \%)$ & \\
\hline Men/Women & $158 / 192$ & $76 / 81$ & $82 / 111$ & $1.27(0.83-1.94)$ \\
\hline Mean age $^{\mathrm{a}} \pm \mathrm{SD}(n=347)$ & $46.8 \pm 18.7$ & $49.4 \pm 18.7$ & $44.7 \pm 18.5$ & $p=0.021^{b}$ \\
\hline $15-34$ yrs & $93(26.6)$ & $34(21.7)$ & $59(30.6)$ & 1.00 \\
\hline $35-54$ yrs & $131(37.4)$ & $57(36.3)$ & $74(38.3)$ & $1.34(0.77-2.31)$ \\
\hline$\geq 55 \mathrm{yrs}$ & $123(35.1)$ & $66(42.0)$ & $57(29.5)$ & $2.00(1.16-3.49)$ \\
\hline Education level $(n=319)$ & & & & $p=0.145^{c}$ \\
\hline Illiterate & $121(34.6)$ & $49(31.2)$ & $72(37.3)$ & 1.00 \\
\hline Literate & $83(23.7)$ & $43(27.4)$ & $40(20.7)$ & $1.57(0.90-2.77)$ \\
\hline Primary complete & 79 (22.6) & $26(16.6)$ & $53(27.5)$ & $0.72(0.40-1.30)$ \\
\hline At least secondary complete & $36(10.3)$ & $26(16.6)$ & $10(5.2)$ & $3.82(1.69-8.63)$ \\
\hline Urban/Rural & $117 / 233$ & $95 / 62$ & $22 / 171$ & $11.9(6.89-20.6)$ \\
\hline Cough and dyspnoea (vs. 1 symptom) & $214(61.1)$ & $103(65.6)$ & $111(57.5)$ & $1.41(0.91-2.18)$ \\
\hline Current smokers & $102(29.1)$ & $38(24.2)$ & $64(33.2)$ & $0.64(0.40-1.03)$ \\
\hline Ever smokers & $202(57.7)$ & $93(59.2)$ & $109(56.5)$ & $1.12(0.73-1.72)$ \\
\hline Mean pack years ${ }^{\mathrm{a}} \pm \mathrm{SD}$ & $9.4 \pm 16.4$ & $10.3 \pm 15.2$ & $8.6 \pm 17.3$ & $p=0.363^{b}$ \\
\hline \multicolumn{5}{|l|}{ GP Diagnosis } \\
\hline COPD & $64(18.3)$ & $34(21.7)$ & $30(15.5)$ & 1.00 \\
\hline Infection & $113(32.3)$ & $25(15.9)$ & $88(45.6)$ & $0.25(0.13-0.49)$ \\
\hline Asthma & $84(24.0)$ & $54(34.4)$ & $30(15.5)$ & $1.59(0.82-3.08)$ \\
\hline TB & $18(5.1)$ & $6(3.8)$ & $12(6.2)$ & $0.44(0.15-1.32)$ \\
\hline Restriction & $46(13.1)$ & $23(14.6)$ & $23(6.7)$ & $=0.98(0.11-1.88)$ \\
\hline Other & $29(8.3)$ & $15(9.6)$ & $10(5.2) \mathrm{S}$ & $1.32(0.52-3.38)$ \\
\hline
\end{tabular}

\section{GP diagnostic competence}

The degree of agreement between GP diagnosis and spirometric outcome was poor, with Kappa $=0.055$ (SE 0.087) and DOR=1.35 (Table 3). Spirometric outcome was 'COPD' in $36(25.4 \%)$ subjects; $27(75.0 \%)$ of these cases were previously

Table 3 Cross-table presenting the degree of agreement between GP diagnosis [GP] and spirometric outcome [SPIRO] for the presence [+] or absence [-] of COPD (Kappa $=0.055, \mathrm{SE} \pm 0.087 ; \mathrm{DOR}=1.35$ ) for all valid spirometries $(n=142)$

\begin{tabular}{ccccc}
\hline & & \multicolumn{2}{c}{ SPIRO } & \\
\cline { 3 - 5 } & & + & - & Total \\
\hline GP & + & 9 & 21 & 30 \\
& - & 27 & 85 & 112 \\
& Total & 36 & 106 & 142 \\
\hline
\end{tabular}

The GP sensitivity is $9 / 36=25 \%$ and specificity is $85 /$ $106=80.2 \%$. The proportion of false-positives is $21 / 106=$ $19.8 \%$, and of false-negatives $27 / 36=75 \%$. unrecognised by the GP (false-negative group). The (incorrect) GP diagnoses for these 27 subjects were: infection $(n=2)$; asthma $(n=11)$; restriction $(n=11)$; and other pathology $(n=3)$. Conversely, spirometric outcome was 'non-COPD' in 106 $(74.6 \%)$ subjects; $21(19.8 \%)$ of these cases were incorrectly diagnosed as COPD by the GP (false-positive group). Spirometric outcomes for this group were: normal lung function $(n=12)$; asthma $(n=3)$; and restriction $(n=6)$. Spirometric outcomes corresponded with GP diagnosis for 9 (25\%) 'COPD' (true-positive group) and 85 (80.2\%) 'non-COPD' (true-negative group) cases.

The false-positive and false-negative groups contained an over-representation of subjects over 55 years $(p=0.001)$ and of subjects with a smoking history of more than five pack years $(p<0.001)$. The rate of newly-detected COPD cases (the falsenegative group) did not differ significantly between men and women, and between rural and urban origin. $43.8 \%$ of subjects with a GP diagnosis of COPD were current smokers; of these, $64.3 \%$ were advised to stop smoking. 
Table 4 Predictors for spirometric outcome of COPD (SPIROCOPD, $n=36$ )

\begin{tabular}{|c|c|c|c|c|}
\hline & $\begin{array}{l}\text { Submitted to } \\
\text { spirometry } \\
(n=142)\end{array}$ & $\begin{array}{l}\text { SPIROCOPD } \\
(n=36)\end{array}$ & OR $(95 \% \mathrm{Cl})$ & PPV (\%) \\
\hline Male sex ${ }^{a}$ & 69 & $24(34.8)$ & $2.71(1.23-5.99)$ & 34.8 \\
\hline Rural setting & 57 & $18(31.6)$ & $1.72(0.80-3.69)$ & 31.6 \\
\hline Dyspnoea and cough (vs. 1 symptom) & 93 & $30(32.3)$ & $3.41(1.31-8.90)$ & 32.3 \\
\hline Only dyspnoea (vs. dyspnoea and cough) & 25 & $2(8.0)$ & $0.18(0.04-0.83)$ & 8.0 \\
\hline Only cough (vs. dyspnoea and cough) & 24 & $4(16.7)$ & $0.42(0.13-1.34)$ & 16.7 \\
\hline Current smokers (vs. never + past smokers) & 37 & $9(24.3)$ & $0.93(0.39-2.21)$ & 24.3 \\
\hline Ever smokers & 85 & $30(35.3)$ & $4.64(1.78-12.1)$ & 35.3 \\
\hline$\geq 5$ pack years (vs. 0 ) & 61 & $28(45.9)$ & $8.65(3.04-24.7)$ & 45.9 \\
\hline Age $\geq 55$ yrs (vs. $15-34$ ) & 59 & $22(37.2)$ & $8.62(1.87-39.7)$ & 37.2 \\
\hline Indoor wood fire & 47 & $11(23.4)$ & $0.86(0.38-1.93)$ & 23.4 \\
\hline
\end{tabular}

\section{Case finding}

Bivariate analysis showed that spirometric outcome of COPD was more prevalent among men (34.8\%) than women $(16.4 \%)$, whereas there was no difference between sexes for mean age and mean pack years. Patients with 'only dyspnoea' were less at risk than patients with 'both cough and dyspnoea'. Age over 55 years, and a history of smoking, increased the odds. Odds were iricreased to a significant level from five pactoearsonwards with a PPM of $45.9 \%$. M Ittiple logistic res.ess on analysis shoved inat only 'preserce cof hoth cough and dyspnoea' and 'more than live pack years' were independent risk factors (Table 4).

\section{Discussion}

In adult patients with respiratory complaints who attended primary care facilities in northern Brazil, we found considerable rates of COPD, diagnosed both by the GP and by spirometry $(18.3 \%$ and $25.4 \%$, respectively). This corresponds with findings from an urban prevalence study from Latin America (which included Brazil), which demonstrated that COPD is indeed already a significant health problem in these areas [6]. From our study it seems that, even though specific training on chronic respiratory diseases is largely lacking, a significant COPD prevalence is already acknowledged. However, at the same time, it appears that the current diagnostic competence of GPs to label and exclude COPD correctly is rather poor. Providing spirometry resulted in a four-fold increase in COPD casefinding and, conversely, a $70 \%$ falsification rate of the GP diagnosis of 'COPD'. Several studies in the industrialised setting have found similar rates when using spirometry for case-finding [15-18]. However, to our knowledge, this is the first time that spirometry has been used in a primary care setting in a developing area with the aim of improving case-finding.

The 'traditional' dialsmoses or asthma and restrictive lung disease cover a large proportion of the actual COPD patienil population. It is important to provide the disonotic tools to discriminate hotve $\in$ EO hem, given the important differences in management strategies. Relatively many errors were made amongst patients over 55 years of age and those with a smoking history, indicating that there is considerable room for improvement in these categories.

It should be noted that only a minority of the GPs who participated in the study had received any specific training in public health and/or primary care (Table 1). Most have been trained within specialist settings; GPs may not be aware of disease prevalence on the population level and they may not have developed the skills to adapt to transitions from communicable to non-communicable diseases - thus contributing to an underestimation of the problem.

The proportion of unacceptable spirometry results in the study (9.6\%) appears to be comparable to previous studies, in which proportions ranged from 10 to $18 \%$ [13,15,22].

Efficient case-finding of patients with COPD in primary care is probably a more realistic approach than screening, especially for the developing world [15]. The first step in establishing an efficient case-finding process is to identify patients who are at risk for developing COPD. In this study, bivariate analysis showed that male sex, a history 
of smoking, age over 55 years, and the presence of two respiratory symptoms, increased the odds significantly. These findings correspond with a casefinding study among smokers by Van Schayck et al., who found that chronic cough, the presence of two symptoms, and the age of the patient, were the strongest predictors [15]. In this study, a smoking history was found to be the strongest risk factor, and an interesting additional finding was that the odds for those with a smoking history were increased significantly from five pack years onwards, suggesting that the studied population might have been exposed to some other significant risk factor such as indoor biomass pollution. A report from China reported that combined exposure to biomass burning and smoking increased the risk of COPD more than four-fold, suggesting a synergistic effect [23]; this phenomenon would put women particularly at risk.

In the group with more than five pack years smoking, COPD prevalence was $45.9 \%$, requiring the testing of 2.2 such patients (adults with cough and/or dyspnoea) to detect one at risk. Multiple regression analysis showed that a smoking history of more than five pack years, and the presence of two (instead of one) principal respiratory symptoms, were the only two independent risk factors. Age became less relevant, probably die to its relation to 'pack years', which was the etrongesi independent predictor of $\angle O P E$ in laduiltion, these

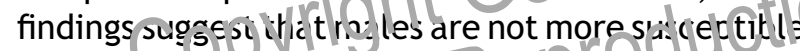
than wanieril ro developino ODPC Whien other features like pack years are taken into account, which is in contrast to earlier studies from the industrialised setting which have labelled male sex as a risk factor [24]. Moreover, it has been suggested that adverse smoking effects on pulmonary function are greater in women than in men [25]. Our study, therefore, provides an incentive for further studies on susceptibility and the impact of combined exposure to biomass burning and smoking in nonWestern populations.

In order to implement spirometry in practice, office spirometers (one for an estimated population of 50,000), and well-trained technicians and physicians are required. Time needed for an adequately performed baseline and reversibility measurement is $\sim 2 \times 7$ minutes (with a 15minute break for salbutamol administration). In a population-based screening program, the costs of detecting one COPD case was estimated to be between US\$469 and US\$953 [26]. Although these costs might seem high for a resourcelimited setting, COPD is in fact ranked amongst the cheaper diseases, just behind hypertension, when similar screening approaches for common diseases are compared [26]. Costs are mainly driven by manpower, which is considerably cheaper in developing countries. Therefore, provided that it is applied to a preselected high-risk population, we believe that implementation of spirometry in a resource-limited general practice can be costeffective. The process of preselection could be aided by a simple self-administered questionnaire to identify high-risk patients, as has been proposed by Price et al. [27]. Before starting up case-finding programs it is essential to assess the burden of disease, and the needs and resources on a local level. Ongoing research will determine the longterm sustainability of spirometry in this setting.

Smoking cessation is the most effective intervention available for reversing the development of COPD. In current practice less than two thirds of smokers with a diagnosis of COPD are advised to stop smoking, leaving considerable room for improvement. Although the Brazilian government has recently taken some actions to discourage smoking [4], attention from local health policymakers and health workers should also prioritise raising awareness of the consequences of smoking and counselling individuallon smoking cessation. Future action chouid be directed towards buincling ápacity on counselling skills and tc $v$ rarc's services by investigating the sustainability of smoking osss itior strategies in a resourcelirin: 2 (1) seting that have already proved to be cost-effective in an industrialised setting [28].

Three possible limitations of this study should be noted. Firstly, the study approach, in which symptomatic patients were selected for spirometry, does not allow for measuring prevalence figures on a population level. Secondly, the volunteering GPs probably represent a young and enthusiastic subset of physicians. However, as they had not received any specific additional training on chronic respiratory disease and spirometry, we estimate that the results regarding their diagnostic competence can be generalized. Thirdly, only $44.9 \%$ of enrolled subjects underwent spirometry. This relatively large drop-out rate was mainly due to logistical reasons, as it was difficult to track down those who did not show up. Overall, patient characteristics did not differ between those tested and those who were not, except for age and education level. A GP-driven selection bias might have occurred if the relevance of spirometry was aimed more at those patients who had a clinical suspicion of chronic respiratory disease, possibly leading to an overestimation of results. In contrast, one can also argue that difficulties with mobility and respiration might have kept the more severely ill out of reach. 
The Global Alliance against Chronic Respiratory Diseases (GARD) has recently been launched by the World Health Organization in order to increase awareness and to develop global action to reduce the burden of chronic respiratory disease in low- and middle-income countries [29]. In addition, GARD and the International Primary Care Respiratory Group Guidelines for Management of Chronic Respiratory Diseases in Primary Care [12], which are also appropriate for the resource-limited setting, emphasize the key role for primary care providers in the global management of respiratory disease. Partnership between these three institutions aims to establish a large health care improvement at relatively low cost by implementing guidelines in a local context. The current study serves as a baseline measurement in order to tailor this process optimally. In the light of scarce existing data, this study adds important new information on current diagnostic competence and strategies to improve COPD case-finding. Although many barriers exist, we believe developed countries can learn a great deal from innovative approaches in resource-limited countries [30].

\section{Acknowledgements}

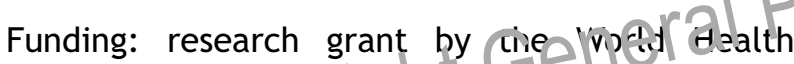
Organization 'Stop Th pingraum', Geneval.

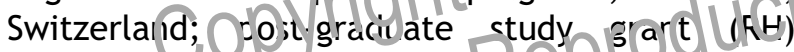
by VSB Beurzenprogramma, the Net

Spirometers by courtesy of BoehringerIngelheim, the Netherlands.

All participating GPs, nurses and health workers in Ceará and Roraima.

Maaike Flinkenflögel for her kind assistance in field work.

\section{References}

[1] Pauwels RA, Rabe KF. Burden and clinical features of COPD. Lancet 2004;364(9434):613-20.

[2] World Health Organization. The world health report 2002: Reducing risks, promoting healthy life. Geneva, Switzerland: World Health Organization; 2002.

[3] Murray CJL, Lopez AD. Global burden of disease (Vol I). Geneva, Switzerland: World Health Organization; 1996.

[4] Shafey O, Dolwick S, Guindon GE. Tobacco Control country profiles 2003 (2nd ed). Atlanta, USA: American Cancer Society, World Health Organization, International Union Against Cancer, 2003. Available at: http://www. globalink.org/tccp (Last accessed April 15, 2006).

[5] Bruce N, Perez-Padilla R, Albalak R. Indoor air pollution in developing countries: a major environmental and public health challenge. Bull World Health Organ 2000; 78(9):1078-92.
[6] Menezes AM, Perez-Padilla R, Jardim JR, et al. Chronic obstructive pulmonary disease in five Latin American cities (the PLATINO study): a prevalence study. Lancet 2005;366:1832-4.

[7] United Nations Development Programme. Human Development Report 2005. Available at: http://hdr. undp.org/reports/global/2005/pdf/HDR05_complete.pdf (Last accessed April 15, 2006).

[8] Instituto Brasileiro de Geographia e Estatística (IBGE), 2003. Available at: http://www.ibge.gov.br. (Last accessed October 10, 2004).

[9] Global Initiative for Chronic Obstructive Lung Disease (GOLD), Brazil. Available at: http://www.golddpoc.com.br (Last accessed October 10, 2004).

[10] Pauwels RA, Buist AS, Calverley PMA, Jenkins CR, Hurd SS; GOLD Scientific Committee. Global strategy for the diagnosis, management, and prevention of chronic obstructive pulmonary disease. NHLBI/WHO Global Initiative for Chronic Obstructive Lung Disease (GOLD) Workshop summary, Am J Respir Crit Care Med 2001;163(5):1256-76.

[11] Celli BR, MacNee W. ATS/ERS Task Force. Standards for the diagnosis and treatment of patients with COPD: a summary of the ATS/ERS position paper. Eur Resp J 2004;23(6):932-46.

[12] Bellamy D, Bouchard J, Henrichsen S, et al. International Primary Care Respiratory Group (ICPRG) Guidelines: Management of Chronic Obstructive Pulmonary Disease (COPD). Prim Care Resp J 2006;15:48-57.

[13] Schermer TR, Jacobs JE, Chav infies Nit ? Al. Validity of spirometric testiñ in ager er ll practice population of patient with thriric obstructive pulmonary disease (C.)PI. Thorax 2003;58(10):861-6.

1147 Chavannes NH, Schermer TR, Akkermans RP, et al. Impact of spiromat y cn GPs diagnostic differentiation and decisionnaking Resp Med 2004;98:1124-30.

[15] van Schayck CP, Loozen JMC, Wagena E, Akkermans RP, Wesseling GJ. Detecting patients at risk of developing chronic obstructive pulmonary disease in general practice: cross sectional case finding study. BMJ 2002;324: 1370-4.

[16] Stratelis G, Jakobsson P, Molstad S, Zetterstrom 0 . Early detection of COPD in primary care: screening by invitation of smokers aged 40 to 55 years. Br J Gen Pract 2004;54(500):201-6.

[17] Pena VS, Miravitlles M, Gabriel R, et al. Geographic variations in prevalence and underdiagnosis of COPD. Chest 2000;118:981-9.

[18] Zielinski J, Bednarek M, the Know the Age of Your Lung Study Group. Early detection of COPD in a high-risk population using spirometric screening. Chest 2001;119: 731-6.

[19] Ministério da Saúde, Departamento de atenção básica. Guia prático do Programa de Saúde da Família. Brasília, Brazil: Ministério da Saúde. 2001.

[20] American Thoracic Society. Standardization of spirometry: 1994 Update. ATS statement. Am J Respir Crit Care Med 1995;152:1107-36.

[21] Quanjer PH, Tammeling GJ, Cotes JE, Pedersen OF, Peslin $\mathrm{R}$, Yeanult JC. Lung volumes and forced ventilatory flows. Report Working Party Standardization of Lung Function Tests, European Community for Steel and Coal. Official Statement of the European Respiratory Society. Eur Respir J Suppl 1993;6:5-40.

[22] Pellegrino R, Decramer M, van Schayck CP, et al. Quality control of spirometry: a lesson from the BRONCUS trial. Eur Resp J 2005;26:1104-9. 
[23] Liu SM, Wang XP, Wang DL, et al. Epidemiologic analysis of COPD in Guangdong province. Zhongua Yi Xue Za Zhi 2005;85(11):747-52.

[24] Feinleib M, Rosenberg HM, Collins JG, Delozier JE, Pokras $\mathrm{R}$, Chevarley FM. Trends in COPD morbidity and mortality in the United States. Am Rev Respir Dis 1989;140:s9-s18.

[25] Xu X, Li B, Wang L. Gender difference in smoking effects on adult pulmonary function. Eur Respir J 1994;7(3):477-83.

[26] van den Boom G, van Schayck CP, van Rutten-Mölken $M P$, et al. Active detection of COPD and asthma in the general population: results and economic consequences of the DIMCA programme. Am J Resp Crit Care Med 1998;158:1730-8.
[27] Price DB, Tinkelman DG, Halbert RJ, et al. Symptom-based questionnaire for identifying COPD in smokers. Respiration 2006;73(3):285-95.

[28] Hall SM, Lightwood JM, Humfleet GL, Bostrom A, Reus VI, Munoz R. Cost-effectiveness of bupropion, nortryptiline, and psychological intervention in smoking cessation. J Behav Health Serv Res 2005;32(4):381-92.

[29] World Health Organization. Global Alliance against Chronic Respiratory Diseases (GARD). Geneva, Switzerland: World Health Organization. Available at: http://www.who. int/respiratory/gard/en/ (Last accessed March 23, 2006).

[30] Berwick DM. Lessons from developing nations on improving health care. BMJ 2004;328:1124-9.

Available online at www.sciencedirect.com

$$
\because \text { ScienceDirect }
$$

\section{Available online at http://www.thepcrj.com}

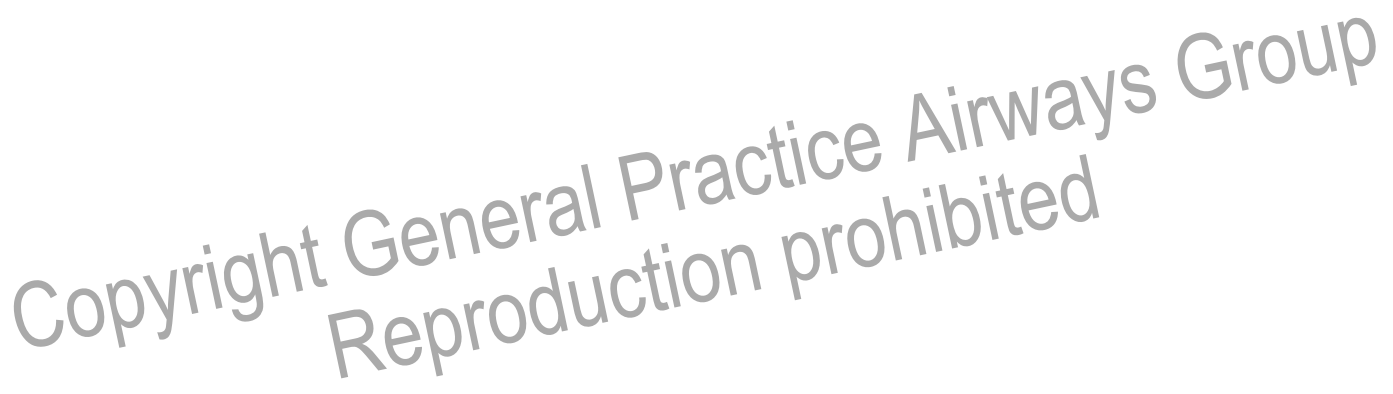

